\title{
Relapsing mitral valve endocarditis - patient preference meets guidelines
}

\section{(1) Siniša Roginićt,2*, (1) Jelena Zajec Gorički', CMarija Čajko', Aleksandar Trbović ${ }^{2}$}

'Zabok General Hospital, Zabok, Croatia

${ }^{2}$ Clinic for Cardiovascular Diseases Magdalena, Krapinske Toplice, Croatia
KEYWORDS: endocarditis, mitral regurgitation.

CITATION: Cardiol Croat. 2019;14(3-4):52. | https://doi.org/10.15836/ccar2019.52

*ADDRESS FOR CORRESPONDENCE: Siniša Roginić, Opća bolnica Zabok i bolnica hrvatskih veterana, Bračak 8 , HR-49210 Zabok, Croatia. / Phone: +385-98-341-234 / E-mail: sinisa.roginic@gmail.com

ORCID: Siniša Roginić, https://orcid.org/0000-0002-0384-8088 • Jelena Zajec Gorički, https://orcid.org/0000-0002-7625-6905 Marija Čajko, https://orcid.org/0000-0001-7084-707X

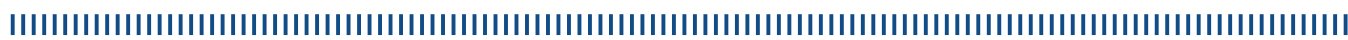

Introduction: Endocarditis is a devastating infection often leading to significant valvular disfunction. Prolonged antibiotic therapy remains a mainstay of treatment but one third of patients require surgery in course of disease. Classic indications are severe valvular disfunction causing heart failure, septic embolization, difficult to control and local propagation of infection..$^{1,2}$

Case report: Our patient has had a mitral valve endocarditis 20 years ago leaving behind presumably moderate mitral regurgitation. Last 3 months she had relapsing fever, anorexia and polyarthralgia which were attributed to her osteoporosis. Transthoracic echocardiography showed deformation and thickening of posterior mitral cusp causing severe mitral regurgitation (MR) described in previous exams, but transesophageal study (TEE) also showed a fresh vegetation on anterior mitral cusp. Streptococcus viridans was repeatedly isolated from blood cultures supporting diagnosis of odontogenic subacute endocarditis. There were no signs of heart failure or peripheral embolization. Patient a priori refused any form of surgical treatment. Vancomycin was administered for 4 weeks (due to penicillin allergy) leading to complete clinical recovery, sterilization of blood cultures and disappearance of anterior mitral cusp vegetation on TEE. After regaining full mobility patient still had no symptoms correlated with a MR.

Discussion and Conclusion: Severe primary MR after endocarditis in the era of valve reparation seems like straightforward surgical indication. We were surprised to find out that the patient's reluctance to surgery was justified by her complete recovery from endocarditis and guidelines. Although MR remained severe, left ventricle is mildly dilated (EDD $56 \mathrm{~mm} / \mathrm{ESD} 27 \mathrm{~mm}$ ), hyperdynamic (EF 66\%), pulmonary hypertension is mild (sPAP $45 \mathrm{mmHg}$ ), and the patient is still in sinus rhythm. Question remains is she truly asymptomatic because recent polyarthritis limited her mobility. Patient was discharged and scheduled for follow up in 3 months.
RECEIVED:

February 28, 2019

ACCEPTED:

March 24, 2019

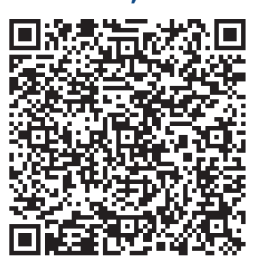

$\square$ Cardiologia Croatica 2019;14(3-4):52.
10. hrvatski dvogodišnji ehokardiografski kongres s međunarodnim sudjelovanjem $10^{\text {th }}$ Croatian Biennial Echocardiography Congress with International Participation Poreč, 16. do 18.5.2019.
LITERATURE IIIIIIIIIIIIIIIIIIIIIIIIIIIIIIIIIIIIIIIIIIIIIIIIIIIIIIIIIIIIIIIIIIIIIIIIIIIIIIIIIIIIIIIIIIIIIIIIIIIIIIII

1. Bin Abdulhak AA, Baddour LM, Erwin PJ, Hoen B, Chu VH, Mensah GA, et al. Global and regional burden of infective endocarditis, 1990-2010: a systematic review of the literature. Glob Heart. 2014 Mar;9(1):131-43. https://doi.org/10.1016/j.gheart.2014.01.002

2. Habib G, Lancellotti P, Antunes MJ, Bongiorni MG, Casalta JP, Del Zotti F, et al; ESC Scientific Document Group. 2015 ESC Guidelines for the management of infective endocarditis: The Task Force for the Management of Infective Endocarditis of the European Society of Cardiology (ESC). Endorsed by: European Association for Cardio-Thoracic Surgery (EACTS), the European Association of Nuclear Medicine (EANM). Eur Heart J. 2015 Nov 21;36(44):3075-3128. https://doi.org/10.1093/eurheartj/ehv319 